\title{
DA PRODUÇÃO DE TABACO AO CULTIVO DE ALIMENTOS: NOVIDADES E TRANSIÇÕES SOCIOTÉCNICAS NA AGRICULTURA FAMILIAR DE PORTO VERA CRUZ - RS
}

\author{
Vanderlei Franck Thies ${ }^{1}$ \\ Marcelo Antonio Conterato ${ }^{2}$
}

\begin{abstract}
RESUMO
O cultivo de tabaco tem importância expressiva no Brasil, entre outras razões, pela destacada posição internacional que o país ocupa em termos de volume produzido e exportado e do grande número de produtores envolvidos. Por outro lado, no cenário internacional destaca-se a crescente restrição a sua produção e consumo, implicando incertezas em relação ao futuro, o que gera a necessidade de reflexões sobre a substituição do seu cultivo. O objetivo do presente trabalho é examinar as estratégias e o processo de transição sociotécnica desenvolvida por agricultores familiares que substituíram o cultivo de tabaco por alimentos. A metodologia contemplou aspectos qualitativos e quantitativos. Foram obtidos dados primários através de estudo de caso junto a Cooperativa dos Agricultores de Porto Vera Cruz - RS, no ano de 2014, através de entrevistas em profundidade, observação participante e questionários estruturados. Utilizando-se a Perspectiva Multinível e a produção de novidades como referências analíticas, o artigo mostra como a emergência de uma novidade organizacional e o acesso aos mercados institucionais catalisaram alterações substantivas nas trajetórias de desenvolvimento rural.
\end{abstract}

Palavras-chave: agricultura familiar, produção de novidades, substituição do tabaco.

\section{FROM TOBACOO PRODUCTION TO FOODS CULTIVATION: NOVELTIES AND SOCIO-TECHNICAL TRANSITIONS IN FAMILY FARMING OF PORTO VERA CRUZ - RS}

\begin{abstract}
Tobacco cultivation has significant importance in Brazil, among other reasons, by the relevant international position that the country occupies in terms of produced and exported volume and the large number of producers involved. On the other hand, the international scenario highlights the increasing restriction of production and

\footnotetext{
${ }^{1}$ Engenheiro Agrônomo (UFPel). Mestre e Doutorando em Desenvolvimento Rural (PGDR/UFRGS). Membro do Grupo de Estudos e Pesquisas Agricultura Familiar e Desenvolvimento Rural - GEPAD. E-mail: vftc3@yahoo.com.br

${ }_{2}$ Geógrafo (UFSM). Mestre e Doutor em Desenvolvimento Rural (PGDR/UFRGS). Professor no Departamento de Economia e Relações Internacionais e do Programa de Pós-Graduação em Desenvolvimento Rural (UFRGS). Membro do Grupo de Estudos e Pesquisas Agricultura Familiar e Desenvolvimento Rural - GEPAD. E-mail: marcelo.conterato@ufrgs.br
} 
consumption, implying uncertainty about the future, which creates the need for thinking about tobacco replacing. The objective of this study is to examine the strategies and socio-technical transition process developed by family farmers who have replaced tobacco cultivation for foods. The methodology included qualitative and quantitative aspects. Primary data were obtained through case study with the Cooperativa dos Agricultores de Porto Vera Cruz - RS, in 2014, through in-depth interviews, participant observation and structured questionnaires. Using the Multilevel Perspective and the production of novelties as analytical references, the article shows how the emergence of a organizational novelties and access to institutional markets catalysed substantive changes in rural development trajectories.

Keywords: family farming, novelty production, tobacco substitution.

\section{INTRODUÇÃO}

O cultivo do tabaco tem importância expressiva no Brasil, envolvendo em torno de 150 mil unidades de produção da agricultura familiar, onde responde por aproximadamente metade da renda global dessas famílias. Além disso, o Brasil é o segundo maior produtor mundial e líder internacional de exportações. Entretanto, apesar de sua importância econômica, o cultivo do tabaco tem gerado intensas discussões no Brasil e em nível internacional. Os malefícios causados ao ambiente e a saúde pública, associados ao consumo e produção, levou a Organização Mundial da Saúde a aprovar em 2003 um tratado internacional denominado Convenção Quadro para o Controle do Tabaco - $\mathrm{CQCT}^{3}$, com vistas a restringir sua produção e consumo ${ }^{4}$.

Em que pese esse contexto de restrição ao cultivo do tabaco, vários estudos apontam, não de forma uníssona, diversos fatores que justificam a manutenção dessa atividade pelos agricultores, entre outros: o rendimento por área; acesso à assistência técnica; as relações de confiança entre empresa e agricultores, impulsionadas pelos técnicos das empresas; disponibilidade de insumos; segurança na inserção mercantil, gerada pela comercialização garantida; estrutura produtiva existente na propriedade; a tradição produtiva e o saber fazer; e a falta de opção (PAULILO, 1990; REDIN, 2011; PERONDI et al., 2011; VARGAS; OLIVEIRA, 2012; TROIAN et al., 2012; RUDNICKI et al., 2014; TROIAN; BECKER, 2015; ANDRADE; SILVA, 2015).

O presente artigo discute a emergência de novidades e as dinâmicas de transições sociotécnicas entre agricultores familiares que substituíram o cultivo de tabaco pela produção de alimentos no município de Porto Vera Cruz - RS. A Perspectiva Multinível (PMN) apresenta-se como aparato intelectual adequado para a análise desses heterogêneos processos de mudança no meio rural por contemplar analiticamente os vetores de ordem macro estrutural e as variáveis de caráter local,

\footnotetext{
${ }^{3}$ Essa convenção foi ratificada pelo Brasil em 2005 e prevê a implementação de medidas que possibilitem alternativas produtivas aos sujeitos envolvidos na produção e comercialização de tabaco. Análise do processo de aprovação da CQCT pode ser vista em Mengel (2011). Decorrente da CQCT o Brasil constituiu o Programa Nacional de Diversificação em Áreas Cultivadas com Tabaco (PNDACT), que é impulsionado desde o MDA (Ministério do Desenvolvimento Agrário) e tem por objetivo incentivar o processo de transição sociotécnica, tendo como princípios: desenvolvimento sustentável, segurança alimentar, diversificação produtiva e participação social (BRASIL, MDA, 2016).

${ }^{4}$ Análises das mudanças no mercado internacional e brasileiro de tabaco e do PNDCT podem ser vistas em Silveira e Dorneles (2010) e em Silva e Tzovenos (2013). Além disso, um balanço institucional das ações do PNDCT pode ser visto em MDA (2010).
} 
além de considerar o papel dos atores e das instituições envolvidas. Ela baseia-se em conceitos como nicho, regime, paisagem e produção de novidades. Para Ploeg et al. (2004) a produção de novidades é um termo chave que, associado aos demais conceitos, constitui-se em potente instrumento interpretativo das dinâmicas rurais contemporâneas.

No município de Porto Vera Cruz ${ }^{5}$, no início do presente século, a produção de tabaco era desenvolvida por agricultores familiares em pequenas propriedades, localizadas em áreas de encosta e em solos sensivelmente degradados. Nesse período, observava-se forte processo de êxodo rural, especialmente dos jovens. Além disso, a condição de empobrecimento, endividamento e subordinação dos agricultores, através de integração vertical com as indústrias de tabaco, impulsionaram estes a buscar alternativas produtivas.

De acordo com Ploeg (2008) frente a contextos que lhes são desfavoráveis a constituição de cooperativas coloca-se como uma alternativa estratégica para o fortalecimento da autonomia dos agricultores. Assim, a capacidade de agência dos agricultores (LONG, 2007) ganha relevância, por expressar os diversos esforços dos agricultores em constituir dinâmicas organizacionais e técnicas que possibilitem a constituição de trajetórias de desenvolvimento rural que lhes sejam mais favoráveis. É no âmago desses processos que muitas novidades emergem, podendo constituir novas trajetórias de desenvolvimento rural.

A busca do "fazer diferente" desses atores destaca a importância da interface dinâmica e mútua entre as transformações nas esferas técnica e social, necessariamente implicadas e imbricadas nesse processo (MARQUES, 2011). No caso da agricultura familiar, segundo Ploeg (2008), a generalização dos impérios alimentares e da industrialização apresenta-se como ameaça a sua reprodução. $O$ mecanismo de integração vertical observado na produção de tabaco pode ser considerado exemplo do controle imperial na agricultura, em função da reduzida autonomia dos agricultores no processo de produção e comercialização. As tensões por ele geradas representam relevante problemática na contemporaneidade rural. Frente a isso, colocam-se importantes questionamentos teóricos relacionados às razões que explicam a permanência dos agricultores nessa atividade, ou, em sentido inverso, quais são os fatores que levam os agricultores a abandonar seu cultivo e ampliar a produção de alimentos? Essa segunda indagação condensa a problemática que impulsionou a realização da pesquisa ora apresentada.

O objetivo do presente trabalho é examinar o processo de transição sociotécnica desenvolvido por agricultores familiares do município de Porto Vera Cruz - RS, desde a constituição de uma cooperativa e a busca de alternativas produtivas e na relação com os mercados, com vistas a substituir o cultivo de tabaco por outras atividades. Pretende-se analisar, através do caso estudado, como a emergência de determinadas novidades catalisam alterações nas trajetórias de desenvolvimento rural entre agricultores familiares produtores de tabaco.

A metodologia para sua realização contemplou aspectos qualitativos e quantitativos. Além de revisão bibliográfica foram obtidos dados primários através de estudo de caso junto aos agricultores associados da Cooperativa dos Agricultores Porto Vera Cruz - COOPOVEC. Foram realizadas entrevistas em profundidade com lideranças e técnicos que assessoram a cooperativa. Além disso, foi realizada

\footnotetext{
${ }^{5}$ O município de Porto Vera Cruz localiza-se no noroeste do Rio Grande do Sul, estando a 538 km da capital Porto Alegre. Foi fundado em 1993, possuindo atualmente uma população de 1727 pessoas e um território de $113 \mathrm{~km}^{2}$. A base da atividade econômica é a agricultura, que é desenvolvida no Bioma Mata Atlântica sendo $88 \%$ dos estabelecimentos rurais de agricultores familiares. Estes ocupam $77 \%$ da área do município e $96 \%$ deles possuem área de até 50 hectares.
} 
observação participante e em setembro e outubro de 2014 foram aplicados 20 questionários estruturados, através de amostra não aleatória por cotas (BARBETTA, 2011), entre associados que participam do Programa de Aquisição de Alimentos da Agricultura Familiar - PAA. Esse número representou $25 \%$ dos agricultores que integraram o projeto daquele ano e $20 \%$ do total de associados da cooperativa.

$\mathrm{O}$ artigo está dividido em cinco seções, iniciando por essa introdução. A segunda seção apresenta os aspectos conceituais que embasam a PMN e a produção de novidades. Na terceira seção é apresenta a trajetória da COOPOVEC como novidade, e na quarta a contribuição do PAA - como janela de oportunidade, que possibilitou a substituição do cultivo de tabaco por alimentos. Na quinta seção se discute mais detidamente esse processo de transição sociotécnica em Porto Vera Cruz - RS. Por fim, apresentam-se algumas considerações com base nos resultados discutidos ao longo do artigo.

\section{A PMN E A PRODUÇÃO DE NOVIDADES}

As mudanças ocorridas ao longo das diversas trajetórias históricas da agricultura podem ser analisadas utilizando-se os conceitos de novidade e de inovação. As inovações tendem a ser incrementais (PLOEG et al., 2004), sem alterações substantivas nas trajetórias do desenvolvimento tecnológico em curso. As novidades implicam mudanças mais radicais, gerando mudanças mais substantivas. De acordo com Oliveira e Araújo (2014) as inovações estão mais vinculadas a processos institucionalizados e lineares de pesquisa e uso do conhecimento, enquanto as novidades estão mais vinculadas à busca cotidiana dos agricultores por soluções aos problemas diários em suas atividades produtivas.

De acordo com Oostindie e Broekhuizen (2008) a inovação é expressão de conhecimento codificado, materializado em um artefato com possibilidade de circulação global, enquanto que uma novidade não tem sua gênese vinculada a um conhecimento codificado, senão a um conhecimento específico, contextualizado localmente, o que em certo sentido dificulta sua circulação e replicação em outros contextos.

A explicação dos processos de transição tecnológica na agricultura é realizada pela PMN com base na inter-relação de conceitos em três níveis: a "paisagem" - representa o nível macro; o "regime sociotécnico" - nível intermediário; e o "nicho" - espaço micro das análises. Para Marques (2011, p. 194) "A abordagem multinível, concebe transições tecnológicas como processos interativos de mudança ao nível de nichos e ao nível de regime sociotécnico, ambos inseridos em uma paisagem exterior de fatores."

A paisagem sociotécnica é a dimensão mais macro da $P M N$, onde o regime e os nichos estão inseridos. A paisagem é definida como diversos fatores macrossociais que representam a estruturação de um "gradiente de forças" ao desenvolvimento das ações, que geram interferências "dinâmicas e recíprocas" no regime e nos nichos. São exemplos: variáveis macroeconômicas, política externa, emigração, etc. O nicho é concebido como um espaço com certo grau de proteção que possibilita a geração e amadurecimento de uma novidade. Nele podem ser desenvolvidas novidades e inovações radicais, enquanto que em nível de regime podem ocorrer inovações incrementais. Eles são o nível local do processo de inovação, onde novidades são desenvolvidas (MARQUES, 2011).

Baseados na formulação de Rip e Kemp (1998), Ploeg et al. (2004) argumentam que regime sociotécnico pode ser definido como a gramática, ou o conjunto de regras que ordena o mundo material e social. Implica a regulação da produção e distribuição do conhecimento, as formas como se definem os problemas, 
os padrões produtivos e tecnológicos, as características dos produtos e maneiras de lidar com os artefatos e as pessoas, tudo isso enraizado em instituições e estruturas. Para Geels (2004) o regime sociotécnico se refere a um conjunto de regras semicoerentes constituídas por diferentes grupos sociais, que servem para orientar e coordenar os atores, contribuindo para estabilização dinâmica do sistema sociotécnico.

Segundo Kemp et al. (1998) apud Marques (2011) o termo regime se refere também a papéis e práticas que não são facilmente dissolvidas. Para Marques (2011, p. 192) além de se referir a rotinas cognitivas partilhadas "O regime tecnológico é caracterizado por produtos estabilizados e tecnologia amplamente aceitas, estoques de conhecimento, práticas de uso, protocolos, técnicas, expectativas, normas e regulações [...]." Por outro lado, o regime pode oferecer certas janelas de oportunidades para novidades, quando atividades de grupos sociais estejam desalinhadas e em tensionamento com o regime (GEELS, 2004). De acordo com Marques (2011) nichos e regimes têm características de campos organizacionais com certas regras que coordenam a ação, entretanto com nível de agregação e estabilidade diferentes. Nos regimes há mais estabilidade e articulação nas regras, enquanto que, nos nichos, há maior instabilidade.

Cabe salientar que existe certa fluidez do nicho em relação ao regime. A constituição do nicho, como espaço com certa proteção para a gestação das novidades, não implica blindagem absoluta em relação ao regime dominante. Certas barreiras às novidades geradas no nicho vão se colocando para que ela possa se expandir e alcançar o nível do regime e da paisagem (MARQUES, 2011). Os regimes sociotécnicos possuem uma estruturação bem constituída, o que dificulta o desenvolvimento de trajetórias alternativas. Essa estruturação é mais frágil em nível de nicho.

Durante o processo de modernização agrícola, ocorrido na segunda metade do século $\mathrm{XX}$, a tecnologia passa a ter papel preponderante no processo de intensificação da produtividade e da produção agrícola, secundarizando o trabalho e ampliando a presença de fatores artificiais nos processos produtivos. Esse conjunto de mudanças levou a ampliação da dependência dos agricultores aos padrões do regime e, por seus limites sociais e ambientais, colocou o tema da sustentabilidade como questão central da agricultura no mundo todo. $\mathrm{Na}$ busca de alternativas sustentáveis emergem muitas novidades (PLOEG et al., 2004).

Através de ciclos ininterruptos de observação, avaliação e modificação de práticas e técnicas os agricultores enfrentam os fatores limitantes da agricultura produzindo novidades (MARQUES, 2011). Segundo Ploeg et al. (2004, p. 2) "A história da agricultura é a história da produção de novidades." De acordo com esses autores as novidades podem ser vistas como sementes da transição, sendo sua produção intrínseca a agricultura e expressão da permanente interação e mútua transformação entre o social e o natural. As novidades podem se materializar em determinados artefatos, mas também em novos dispositivos organizacionais, ou arranjos institucionais particulares (OOSTINDIE; BROEKHUIZEN, 2008). O estudo de Gazzola (2012) sobre agroindústrias familiares evidencia como novidades organizacionais produzem alterações significativas nas dinâmicas rurais. Esse também parece ser o caso dos associados da COOPOVEC.

De acordo com Ploeg et al. (2004), uma novidade pode ser definida como certo desvio de rota, como modificação ou, algumas vezes, interrupção em rotinas existentes. Podem surgir a partir de um novo olhar sobre determinada prática, ou consistir nova prática, sendo, principalmente, um novo jeito de fazer e pensar as rotinas, potencialmente melhor que o modo, até então, desenvolvido. 
Por fim, cabe destacar, conforme argumenta Marques (2011, p. 199), que uma novidade não se restringe à mudança de uma atividade tradicional por uma pouco usada "[...] a inovatividade se estende aos modos de fazer, de comercializar, de estabelecer relacionamentos com pesquisadores, extensionistas, além, de constituir formas diversas de construção dos conhecimentos que orientam suas práticas." A produção de novidades pode incluir a introdução de tecnologias ou conhecimentos externos, mas se dá, principalmente, como fruto da ação cotidiana dos agricultores (OLIVEIRA; ARAÚJO, 2014). A partir do caso estudado sustentamos que as mudanças observadas decorrem das alterações nas rotinas sociais e produtivas dos agricultores, reposicionando esses sujeitos na relação com os mercados, com as políticas públicas e outros atores.

Ao valorizar a ação dos sujeitos a PMN estabelece diálogo convergente com a perspectiva orientada aos atores (OLIVEIRA et al., 2011), para quem os agricultores são ativos processadores de informações e desenvolvedores de estratégias, que se estabelecem nas relações mantidas com outros atores e com instituições. De acordo com Long (2007) o que define a condição de ator é a capacidade de agência, onde os sujeitos não são passivos e inertes, sob os quais forças estruturais externas agem e determinam unilateralmente sua condição de existência.

Neste sentido, ser ator é uma condição social conquistada, não sendo um atributo inerte. Essa condição é alcançada pelos indivíduos, ou grupos, à medida que estabelecem relações e interações sociais, construindo agência, ao agir, ou reagir, em contextos adversos e situações hostis, através da mobilização de recursos e capacidades, além do desenvolvimento de estratégias que possibilitem 'fazer diferente'. Os atores sociais podem ser agricultores individuais, grupos ou coletivos sociais (SCHNEIDER; GAZOLLA, 2011). De acordo com Long e Ploeg (1994) as diferentes configurações de organização social emergem e resultam das interações, negociações e lutas sociais entre os diferentes atores, incluindo as lutas imediatas e presentes, como aquelas mais distantes e não presenciais. Todas elas influenciam a configuração da organização social, afetando as ações e os resultados. Na seção que segue iniciamos a análise das transições sociotécnicas decorrentes do exercício da capacidade de agência dos agricultores de Porto Vera Cruz frente à produção de tabaco.

\section{A TRAJETÓRIA DE UMA NOVIDADE}

A COOPOVEC foi fundada em Porto Vera Cruz, no ano de 2004. O objetivo que impulsionou sua constituição foi a busca de alternativas produtivas e de comercialização à produção de tabaco, que na época era o carro chefe das atividades produtivas. Dos 20 sócios fundadores, 18 eram produtores de tabaco. Eles buscavam, com a criação da cooperativa, impulsionar dinâmicas que lhes permitissem implantar alternativas produtivas, que possibilitassem a substituição do cultivo de tabaco por outras culturas e, com isso, o distanciamento das empresas fumicultoras.

De acordo com dados da AFUBRA (2015) a maior parte do tabaco produzido no Brasil é destinado a exportação (cerca de $85 \%$ ) e sua produção (cerca de $95 \%$ ) se concentra nos estados do Sul do país. Essa produção é realizada por pequenos produtores (atualmente envolve cerca de 180 mil agricultores familiares) e controlada por um pequeno grupo de grandes empresas transnacionais através do sistema de integração. Nesse sistema, os agricultores possuem reduzida autonomia, pois a indústria faz a intermediação ou fornece diretamente os insumos (sementes, adubos, equipamentos, assistência técnica, financiamento, etc.) em troca da venda 
integral e exclusiva da produção, garantida por relações contratuais e de confiança (SILVA, 2002; DESER, 2010; RUDNICKI, 2012; ANDRADE, 2014; TROIAN; BECKER, 2015; LUDTKE et al., 2016).

Os agricultores familiares de Porto Vera Cruz que produziam tabaco vivenciavam essa condição de subordinação e, por isso, buscavam alternativas. Ao estudar o caso dos produtores de tabaco que desenvolvem ações de diversificação produtiva em Santa Cruz do Sul, Ludtke et al. (2016) argumentam que, essa busca decorre da autoconfrontação dos agricultores com os diversos riscos decorrentes da sua participação na cadeia produtiva do tabaco, entre eles, o da subordinação e reduzida autonomia. Para essas autoras a diversificação produtiva é uma estratégia desenvolvida pelos agricultores para fazer frente a esses riscos. Argumentamos que a constituição da COOPOVEC vem nessa mesma perspectiva.

A formação dessa cooperativa representou, em sua gênese como novidade, uma promessa (PLOEG, 2008) de melhorias nas condições de vida para esses agricultores. A constituição da cooperativa também representou uma novidade no sentido de expressar uma quebra de rotina no cotidiano dos agricultores. Essa quebra, no período inicial, esteve mais centrada na dimensão social, pois implicou uma alteração substantiva nas rotinas individualizadas dos agricultores, que foram tencionadas e tiveram que ceder espaço para dinâmicas de caráter grupal, com a constituição de dispositivos coletivos, a formação de redes, novas regras de referência e novas institucionalidades (PLOEG, 2008; OLIVEIRA; ARAÚJO, 2014; OOSTINDIE; BROEKHUIZEN, 2008). Posteriormente, com o avanço do trabalho da cooperativa, as rotinas técnicas nas atividades produtivas também sofreram alterações.

De acordo com Ploeg (2008) as novidades precisam de tempo para ser geradas e podem resultar em fracasso, ou demorar a surtir efeito. No caso da COOPOVEC observou-se que os primeiros anos de sua existência foram marcados pela busca de alternativas ao tabaco. Inicialmente foi estimulada a fruticultura e também ganhou espaço a olericultura, mas um dos grandes limitadores dessas atividades era a dificuldade de comercialização da produção. Essa dificuldade ganhava especial relevo entre os agricultores familiares produtores de tabaco, devido à comercialização ser garantida e organizada pelas empresas integradoras, o que gera historicamente um quadro de pouca densidade nos conhecimentos e habilidades comerciais desses agricultores, por estarem em uma posição de subordinação no processo de comercialização.

No processo inicial de sua constituição as conexões locais estabelecidas pela cooperativa cumpriram papel muito importante. De acordo com Marques (2011, p. 200) "A dinâmica da gênese das novidades emerge da evolução cotidiana das inúmeras práticas desenvolvidas pelos agricultores, assim como da mobilização de um conjunto de relações sociais que configuram o próprio processo de aquisição e geração de conhecimentos." As relações estabelecidas pela COOPOVEC possibilitaram maior acesso à assistência técnica ${ }^{6}$, disponibilizada pela Secretaria Municipal da Agricultura e Empresa de Assistência Técnica e Extensão Rural EMATER, além do suporte da Cooperativa de Eletrificação Rural Fronteira Noroeste LTDA - COOPERLUZ, da Associação Regional de Desenvolvimento - AREDE e do Sindicato dos Trabalhadores Rurais. Essas entidades estimularam e apoiaram o fortalecimento da perspectiva estratégica apontada pela COOPOVEC e no período inicial cumpriram papel muito importante como suportes estruturais, sobretudo, como

\footnotetext{
${ }^{6}$ Em relação à assistência técnica observou-se que 70\% dos agricultores, em 2014, receberam esse serviço, destacando-se a EMATER e a Secretaria Municipal de Agricultura como as principais entidades prestadoras desse serviço.
} 
fonte de conhecimentos e informações para o avanço do trabalho da emergente cooperativa. Ludtke et al. (2016) apontam nesse mesmo sentido, destacando a importância da constituição de uma rede de atores para dar suporte e impulsionar as ações de constituição de alternativas ao tabaco.

É a partir de 2006 que a intensidade das atividades da cooperativa muda significativamente, pois nesse ano são iniciadas suas experiências com os mercados institucionais ${ }^{7}$, especificamente com o PAA $^{8}$.

\section{O PAA COMO UMA JANELA DE OPORTUNIDADE}

Em termos analíticos, o PAA representou uma janela de oportunidade (GEELS, 2004) surgida no ambiente exterior ao nicho, que pode ser aproveitada em função da novidade sócio organizativa que foi a constituição da COOPOVEC. A cooperativa foi o aparato organizativo que viabilizou a participação dos agricultores no PAA.

Constatou-se que o PAA efetivamente cumpriu um papel transformador na dinâmica da cooperativa e da vida dos associados ${ }^{9}$. O primeiro projeto, programado para três meses, foi realizado em 2006 e 2007, totalizando $R \$ 17.000,00$. A partir daí a cooperativa passou a desenvolver projetos maiores ${ }^{10}$, que davam garantia de compra aos agricultores, o que impulsionou fortemente o desenvolvimento do cultivo de frutas e hortaliças em substituição ao cultivo do tabaco. Isso estimulou a produção dos agricultores sócios e também a participação de novos agricultores, ocorrendo o aumento do número de associados da cooperativa (em 2014 eram 102 sócios, ou seja, cinco vezes mais que o número de sócios-fundadores em 2004).

A relação entre agricultores e as empresas de tabaco representa uma das diversas possibilidades de inserção destes nos mercados. Nesse caso, os agricultores estão em uma posição de reduzida autonomia, todavia segundo Conterato et al. (2011), os mercados também podem contribuir para o fortalecimento da autonomia dos agricultores. Os mercados são espaços sociais resultantes da interação de diversos atores, entre eles os agricultores familiares, que tomam parte ativa nesse jogo. A mercantilização implica negociação e disputas, tanto materiais como simbólicas, para o controle dos mercados, compondo processos heterogêneos, complexos e não lineares.

A opção dos agricultores de Porto Vera Cruz pelo PAA deu-se devido a esse programa efetivamente garantir a comercialização da produção, o que implicou o reordenamento da relação dos agricultores com os mercados. Nesse sentido, as

\footnotetext{
7 Segundo Grisa (2010, p. 103) designa-se mercado institucional como sendo uma "[...] configuração específica de mercado em que as redes de troca assumem uma estrutura particular, previamente determinada por normas e convenções negociadas por um conjunto de atores e organizações, onde o Estado geralmente assume um papel central, notadamente através de compras públicas."

${ }^{8} \mathrm{O}$ principal objetivo do PAA é promover o acesso aos alimentos para as populações em situação de insegurança alimentar e a inclusão social e econômica no campo, pelo incentivo ao desenvolvimento da agricultura familiar. Além disso, visa contribuir à formação de estoques estratégicos de alimentos e facilitar o processo de comercialização em âmbito local, adquirindo produtos típicos da agricultura familiar de cada local e na hora oportuna. Seu funcionamento ocorre através da compra, com dispensa de licitação, que o Governo Federal faz dos agricultores familiares e sua posterior entrega às populações em condição de insegurança alimentar. Os recursos que viabilizam esse programa são oriundos do Orçamento Geral da União. Para análises pormenorizadas do PAA ver Grisa (2012), Rocha e Anjos (2013) e Porto (2014).

${ }^{9}$ Em termos logísticos a COOPOVEC organiza o recolhimento dos produtos e seu transporte até os locais de entrega. Para isso, contrata um prestador de serviços de transporte, visto não possuir caminhão próprio. Os produtos são agrupados pelos agricultores em pontos de coleta nas comunidades, por onde o caminhão passa para fazer o recolhimento, em datas e horários previamente estipulados. Os gastos com transporte e os demais custos são rateados e cobertos entre os participantes do projeto.

${ }^{10} \mathrm{O}$ projeto para os anos de $2013-2014$ englobava 80 associados e tinha valor total de $\mathrm{R} \$ 380.000,00$.
} 
mudanças observadas não decorrem da introdução de um novo artefato produtivo, mas da constituição de uma nova dinâmica socioeconômica (PLOEG, 2008; OLIVEIRA; ARAÚJO, 2014). Essa garantia da comercialização da produção oferecida pelo PAA na atualidade segue sendo apontada pela direção da cooperativa como elemento fundamental para a elevada adesão dos agricultores ao programa, além da negociação e acordo prévio do preço dos produtos. Isso reposicionou os agricultores na negociação da venda de seus produtos, com ampliação de sua autonomia comercial.

Também contribuiu para o crescimento da adesão ao programa o fato do PAA adquirir produtos que os agricultores tinham experiência em produzir, implicando apenas um rearranjo de elementos produtivos já existentes passando a produzir para venda produtos que antes já eram cultivados, sobretudo, para o consumo da família. Os primeiros projetos tinham duração inferior a um ano e possuíam valores totais que foram gradativamente sendo aumentados. Todos os projetos executados via PAA foram através da modalidade Compra com Doação Simultânea.

Paralelo ao crescimento dos valores totais contratados e do número de associados participantes nos projetos do PAA, a cooperativa buscou outras atividades e fontes de financiamento, conseguindo alavancar recursos para a instalação de uma microdestilaria de álcool, que já está em funcionamento. Além disso, está finalizando a construção de uma agroindústria para processamento de frutas, representando o que Oliveira e Araújo (2014) denominaram de inovações decorrentes. Esses novos equipamentos implicam novos arranjos sociais e de trabalho naquilo que Ploeg (2008, p. 215) denominou de "[...] um conjunto bem integrado de mudanças interligadas que têm impactos multidimensionais de grande alcance na prática agrícola e na transição."

Cabe destacar outras mudanças observadas na dinâmica produtiva. Para $90 \%$ dos agricultores entrevistados o ingresso no PAA gerou aumento da área cultivada para venda (para $71 \%$ deles, esse programa foi o maior responsável por esse aumento), o que representa ampliação da renda familiar. Essa mudança corrobora os resultados do estudo de Ludtke et al. (2016), que aponta a necessidade da diversificação não apenas produtiva, mas também das fontes de renda, para a substituição do cultivo do tabaco.

Além disso, a participação no programa também contribuiu diretamente para a ampliação da segurança alimentar de um terço das famílias consultadas, para quem, após o ingresso no PAA, ocorreu aumento na área cultivada para consumo da família, sendo que $86 \%$ destes consideraram esse programa como o maior responsável por esse aumento. Atualmente $65 \%$ dos agricultores consultados utilizam irrigação e 54\% destes passaram usar essa tecnologia em função do PAA, representando expressiva alteração nos sistemas produtivos.

\section{A SUBSTITUIÇÃO DO TABACO}

Dentre os agricultores entrevistados, durante a pesquisa, $75 \%$ cultivavam tabaco antes da participação no PAA e após o ingresso no programa $10 \%$ prosseguem com seu cultivo. O PAA é apontado como o principal catalizador dessa mudança. Tem-se, portanto, uma redução bastante significativa no cultivo do tabaco e ampliação do cultivo de variedades alimentares, que são adquiridas pelo PAA. Os cultivos que substituíram o tabaco e que são entregues no PAA envolvem a produção de mais de vinte tipos de hortaliças, onze tipos de frutas, além de melado, açúcar mascavo, pães e cucas. Essa variedade de produtos comercializados atende 
a uma condição apontada por Andrade e Silva (2015) para a substituição do cultivo do tabaco, que é a diversificação produtiva.

Essa mudança operada pelos agricultores possibilitou a constituição de uma trajetória diferente da apontada pelo regime sociotécnico dominante (GEELS, 2004) e constituiu um caminho novo, com ampliação da autonomia dos agricultores (PLOEG, 2008). A substituição do cultivo de tabaco por cultivos alimentares alinhase a perspectiva apontada por Goodman (2003), para quem está em curso um movimento de contraposição ao controle imperial e uma virada de qualidade nas dinâmicas alimentares.

Os alimentos adquiridos pelo PAA são entregues em dois municípios vizinhos, fortalecendo os vínculos entre a produção e o consumo local ${ }^{11}$. Esse movimento de mudança também expressa o reconhecimento da importância das cadeias alimentares curtas, que têm ganhado destaque ao sublinhar aspectos como a necessidade da reconexão entre a produção e o consumo local de alimentos como argumentam Ilbery et al. (2005) e Triches e Schneider (2010). Essa perspectiva aponta que, impulsionado pelos problemas do modelo produtivista dos impérios alimentares, uma nova geografia alimentar estaria surgindo. As mudanças observadas em Porto Vera Cruz, de substituição de cultivo de tabaco por alimentos, expressa o desenvolvimento de iniciativas de desenvolvimento local, onde são estimuladas e intensificadas as relações entre produção e consumo, materializando a perspectiva sinalizada por esses autores.

Em termos de conjunto do município, tem-se na Tabela 1 a evolução da área total cultivada com tabaco em Porto Vera Cruz. Pode-se observar uma inflexão na tendência de crescimento em 2006, ano em que a COOPOVEC passa a executar o PAA. A partir desse ano a tendência de crescimento observada no período 2000 a 2006 se inverte, ocorrendo redução na área total de tabaco plantada no município. Em termos gerais essa tendência também é observada para o Estado do Rio Grande do Sul e para o Brasil, sinalizando que existem variáveis gerais que incidem sobre a variação da área cultiva com tabaco. Todavia, observam-se grandezas de variação bastante diferentes, pois no caso de Porto Vera Cruz, no período de 2000 a 2006, a área plantada triplica e no período de 2006 a 2014 a área diminui pela metade, variações que ocorrem com magnitudes diferentes no RS e no Brasil.

Tabela 1 - Evolução da área plantada (ha) com tabaco no município de Porto Vera Cruz, no RS e Brasil entre os anos de 2000 e 2014.

\begin{tabular}{lccc}
\hline & Porto Vera Cruz & RS & Brasil \\
\hline 2000 & 70 & 145.480 & 310.633 \\
2002 & 133 & 165.213 & 344.879 \\
2004 & 200 & 229.007 & 462.391 \\
2006 & 230 & 243.249 & 497.899 \\
2008 & 150 & 216.196 & 432.697 \\
2010 & 120 & 220.512 & 450.076 \\
2012 & 120 & 202.731 & 410.675 \\
2014 & 100 & 205.306 & 416.668 \\
\hline
\end{tabular}

Fonte: IBGE-SIDRA, 2016.

\footnotetext{
${ }^{11}$ No projeto 2013 - 2014 os alimentos eram enviados para a cidade de Santa Rosa, onde eram entregues 758 cestas e para Porto Lucena, onde se entregavam 121 cestas, totalizando 879 cestas. Com a divisão dos beneficiários em grupos menores a cooperativa realizava entregas semanais dos alimentos para atender toda demanda. Para as entregas a COOPOVEC contou com a parceria da Pastoral da Criança nos dois municípios, até o ano de 2014. A partir de 2015 os Centros de Referência e Assistência Social - CRAS assumiram essa tarefa. No caso de Santa Rosa a COOPOVEC seguiu contando com o apoio do Centro Assistencial Sagrada Família na distribuição dos alimentos, não sendo mantida a parceria com a Pastoral da Criança.
} 
O tabaco, que era produzido por cerca de $90 \%$ dos associados no período de criação da cooperativa, hoje é produzido por cerca de $10 \%$ dos associados, o que demonstra sensível redução no uso desse canal de comercialização. Com intensidade menor, essa mudança também foi observada em relação ao uso de outros canais de venda. Como se pode ver na Tabela 2 , no caso da venda para agroindústrias (leite e grãos), ela era realizada por $80 \%$ dos agricultores antes da participação no PAA. Após o ingresso no programa, esse número passou para $40 \%$ e, no futuro, apenas $25 \%$ dos agricultores pretendem seguir vendendo para essas agroindústrias. No caso do tabaco, apesar de 10\% dos agricultores consultados ainda utilizarem esse canal de comercialização no período da pesquisa, nenhum deles pretende, no futuro, seguir produzindo essa cultura. Ou seja, a perspectiva futura é de total abandono desse cultivo.

Tabela 2 - Taxa relativa de uso dos canais de comercialização entre associados da COOPOVEC antes e depois do PAA e perspectivas de uso no futuro, 2014.

\begin{tabular}{lccc}
\hline Canais de comercialização & $\begin{array}{c}\text { Antes do } \\
\text { PAA }\end{array}$ & $\begin{array}{c}\text { Com o } \\
\text { PAA }\end{array}$ & $\begin{array}{c}\text { Usar no } \\
\text { futuro }\end{array}$ \\
\hline Para agroindústrias (leite ou grãos - soja, milho, trigo) & $80 \%$ & $40 \%$ & $25 \%$ \\
Integração com empresas (fumo) & $75 \%$ & $10 \%$ & $0 \%$ \\
\hline
\end{tabular}

Fonte: dados da pesquisa, 2014.

Vargas e Oliveira (2012) apontam a ausência de canais de comercialização para os cultivos tradicionais dos agricultores como um dos fatores que contribuem para dificultar a substituição do tabaco por outros cultivos. A pesquisa realizada junto a COOPOVEC evidenciou claramente que o acesso aos mercados institucionais foi o fator preponderante na substituição do cultivo do tabaco por cultivos alimentares. Essa conclusão vai em perspectiva diversa, embora não antagônica, da apontada por Ribeiro et al. (2015), em caso estudado no município de São Mateus do Sul (PR), que apontou a gestão da propriedade como o fator preponderante para o abandono do cultivo do tabaco.

Diversos estudos apontam a existência de grande diversidade e heterogeneidade na configuração das dimensões sociais e produtivas entre agricultores familiares produtores de tabaco (RUDNICKI; GUERIN, 2014; SARTORELLI; RAMBO, 2014; FREITAS et al., 2015; TROIAN; BECKER 2015). Por conta dessa diversidade, acredita-se que não exista apenas um fator com capacidade de catalisar esse processo de substituição do cultivo de tabaco. Ainda que um fator específico possa se destacar nesse processo, em determinada circunstância, como o acesso aos mercados institucionais em Porto Vera Cruz, a inserção desse mesmo fator em outro contexto poderá produzir resultados adversos, dada essa diversidade de configurações sociais e produtivas presente entre os produtores.

Frente a isso, destacam-se os argumentos de Vargas e Oliveira (2012), que apontam a necessidade das iniciativas de diversificação das atividades produtivas, entre produtores de tabaco, estar inseridas em ações mais amplas de desenvolvimento rural, não podendo estar alicerçada sobre uma única dimensão. Por exemplo, esses autores apontam o limite no tamanho das áreas agrícolas disponíveis como um fator limitante ao processo de diversificação produtiva dos agricultores produtores de tabaco. Perondi et al. (2011), em estudo no sudoeste do Paraná, também constataram que a área média dos estabelecimentos de exfumicultores é maior que a de fumicultores, sendo o tamanho limitado dos 
estabelecimentos um fator que dificulta a substituição do cultivo do tabaco, devido aos maiores rendimentos por unidade de área propiciados por esse cultivo. No caso dos associados da COOPOVEC, o limite do tamanho dos estabelecimentos rurais também fica bastante evidente ${ }^{12}$, embora não tenha impedido a diversificação produtiva e a substituição do cultivo de tabaco.

Por outro lado, Perondi et al. (2011), em estudo realizado sobre meios de vida alternativos ao cultivo do tabaco, apontam que a renda não é o único parâmetro considerado pelos agricultores para a substituição do cultivo de tabaco. Todavia, argumentam que a obtenção de uma fonte de rendimento alternativa, compatível com a renda gerada pelo tabaco, é uma das questões consideradas pelas famílias de agricultores, além da melhoria na qualidade de vida, nesse processo de decisão. Os resultados da pesquisa em Porto Vera Cruz corroboram esse argumento, pois a garantia de venda e de renda, representada pelo PAA, é apontada pelos agricultores como um elemento central no processo de decisão que culminou com o abandono do cultivo do tabaco.

A grande redução observada no cultivo de tabaco em Porto Vera Cruz implicou uma mudança substantiva no conjunto das rotinas produtivas e nas dinâmicas comerciais dos agricultores, que são consequências da introdução da COOPOVEC como novidade. Especificamente, em relação aos canais de comercialização utilizados pelos associados da cooperativa, ficou evidente a redução do uso de canais mais longos e ampliação do uso de canais mais curtos.

A venda direta aos consumidores, organizada pela cooperativa após os primeiros contratos com o PAA, através de uma feira ${ }^{13}$ em um município vizinho, constitui um importante exemplo daquilo que Ploeg (2008) denominou de novidades originando outras novidades, que se encadeiam em redes e se desenvolvem em direções inesperadas. Resultados semelhantes, em relação à construção social de mercados, foram observados por Oliveira e Araújo (2014) ao analisar o caso de uma cooperativa de produtores ecologistas, em Antônio Prado - RS.

Outra dimensão que evidencia as alterações nas rotinas sociais e técnicas dos agricultores, decorrentes da introdução de novidades, está associada à realização de investimentos produtivos. Entre os associados da COOPOVEC que participam do PAA, 79\% deles apontam esse programa como "o principal fator", ou "o PAA junto como outros fatores", como o principal elemento que levou os agricultores a buscar financiamento público junto à rede bancária. Isso evidencia a relevância do programa como fator indutor da tomada de financiamento, que está associado às necessidades de investimentos para adaptação dos sistemas produtivos no processo de reconversão da produção de tabaco por alimentos.

Por fim, cabe destacar que os aspectos inovadores introduzidos pela COOPOVEC também se evidenciam em alterações nas relações estabelecidas entre os agricultores e os sujeitos externos (pesquisadores, extensionistas) e nas formas de construir os conhecimentos que orientam as práticas (MARQUES, 2011). A cooperativa permite a significação diferenciada da realidade e a construção de caminhos alternativos aos padrões do regime sociotécnico dominante. Caminhos esses, até então, não perceptíveis aos agricultores e que sua descoberta, conforme também argumentam Andrade e Silva (2015), torna mais intensa a reação dos

\footnotetext{
${ }^{12}$ Entre os agricultores consultados, $65 \%$ são proprietários de áreas de terra inferiores ao módulo fiscal do município. Outros $20 \%$ não são proprietários de terra e apenas $15 \%$ são proprietários de áreas superiores ao módulo fiscal. Além disso, do conjunto de agricultores consultados, $60 \%$ possuem área total disponível (área própria mais área arrendada) inferior ao módulo fiscal do município.

${ }_{13}$ Essa feira é gerenciada pela cooperativa e ocorre semanalmente na cidade de Porto Lucena. Nela são comercializados diversos produtos hortifrutigranjeiros de parte dos associados.
} 
agricultores, como agentes, no sentido diversificar a produção, ou substituir o cultivo do tabaco.

\section{CONSIDERAÇÕES FINAIS}

A redução do cultivo de tabaco e sua substituição por cultivos alimentares, para a venda e para o consumo das famílias, expressa uma significativa reorganização nas unidades de produção e a constituição de um novo arranjo dos fatores produtivos manejados por esses agricultores. $O$ trabalho cooperativo e as novas dinâmicas comerciais experimentadas e vividas por esses agricultores expressam alterações qualitativas de grande envergadura na vida dessas famílias. Essas mudanças, observadas durante a pesquisa e expressas nesse artigo, evidenciam intenso processo de transição nas atividades produtivas e também na dinâmica social entre os associados da cooperativa que participaram do PAA.

A constituição da COOPOVEC, quebrando as regras da ação individualizada dos agricultores, contrapondo-se ao regime sociotécnico moderno da produção de tabaco e prometendo melhoras nas condições de vida dos agricultores, caracteriza-se como uma novidade por, ao aproveitar a janela de oportunidade que representou o PAA, alterar substantivamente as rotinas sociais e econômicas dos agricultores familiares de Porto Vera Cruz. Como mostrou-se nesse artigo, os efeitos da introdução dessa novidade tiveram caráter multidimensional, alterando as rotinas de produção e de comercialização agropecuária, bem como as dinâmicas sociais dos agricultores.

A COOPOVEC foi a novidade sócio organizativa que serviu de base para o impulso da transição sociotécnica em Porto Vera Cruz, que levou a substituição do cultivo de tabaco por cultivos alimentares. Como janela de oportunidade, o PAA também cumpriu papel fundamental nesse processo de transição. Isso reforça a importância do apoio à diversificação dos circuitos de comércio e dos mercados institucionais para a constituição de novas trajetórias de desenvolvimento rural.

Embora tenha sido o elemento catalizador das mudanças em Porto Vera Cruz, o acesso aos mercados institucionais não necessariamente vai promover o mesmo padrão de alterações em outros contextos, dada a heterogeneidade existente entre os produtores de tabaco. Todavia, no caso estudado, ficou bastante evidente a centralidade que o acesso ao PAA teve, através da organização dos agricultores em cooperativa, no processo de transição sociotécnica.

Por fim, procurou-se demonstrar que a COOPOVEC, como novidade, produziu mudanças significativas nas dinâmicas sociais e produtivas dos agricultores de Porto Vera Cruz. Isso se deu, sobretudo, através do acesso possibilitado aos mercados institucionais, mas também em função da cooperativa fazer frente a outros dois importantes fatores limitantes à substituição do cultivo do tabaco, que é o carente nível de organização dos agricultores e o acesso incompleto as informações sobre o setor produtivo. Essa observação vem na mesma perspectiva dos resultados do estudo de caso realizado por Andrade e Silva (2015), em Arvorezinha (RS) Ludtke et al. (2016), o que reforça a centralidade da organização dos agricultores nas estratégias de desenvolvimento rural e para as políticas públicas que visem à diversificação ou a substituição do cultivo de tabaco.

As significativas mudanças observadas nos sistemas produtivos e nas dinâmicas sociais em Porto Vera Cruz avançam na perspectiva da sustentabilidade e ampliação da autonomia dos agricultores. Elas decorrem fundamentalmente da combinação de dois elementos: o desejo de mudança e a agência dos atores locais, expresso na organização de uma cooperativa; o apoio do Estado, através de políticas públicas específicas de apoio aos agricultores familiares nesse processo de 
transição. Ou seja, nos termos da PMN, da articulação sinérgica entre a aspiração por mudanças dos atores locais, ao nível de nicho, com o surgimento de oportunidades externas, ao nível de regime.

\section{REFERÊNCIAS}

AFUBRA - Associação dos Fumicultores do Brasil. Fumicultura no Brasil. Disponível em: <http://www.afubra.com.br/home.html>. Acesso em: mar. 2016.

ANDRADE, M. M. Racionalidade limitada entre agricultores familiares produtores de tabaco no Vale do Rio Pardo - RS. 2014. Dissertação (Mestrado em Desenvolvimento Rural), Programa de Pós-Graduação em Desenvolvimento Rural, Faculdade de Ciências Econômicas, UFRGS, Porto Alegre, 2014.

ANDRADE, M. M. de; SILVA, L. X. da. Racionalidade limitada e agricultores familiares produtores de tabaco no Vale do Rio Pardo/RS. REDES, Santa Cruz do Sul, v. 20, n. 3 - Suplemento, p. 76-93, set./dez. 2015.

BARBETTA, P. A. Estatística aplicada às ciências sociais. Florianópolis: Ed. UFSC, 2011.

BRASIL. Ministério do Desenvolvimento Agrário - MDA. Programa Nacional de Diversificação em Áreas Cultivadas com Tabaco - PNDACT. Disponível em: <http://www.mda.gov.br/sitemda/secretaria/saf-projetosespeciais/programa-nacionalde-diversificação-em-áreascultivadas-com-tabaco>. Acesso em: jan. 2016.

BRASIL. Ministério do Desenvolvimento Agrário do Brasil - MDA. Ações do Ministério do Desenvolvimento Agrário para a diversificação da produção e renda em áreas cultivadas com tabaco no Brasil. Brasília, MDA, 2010.

CONTERATO, M. A. et al. Mercantilização e mercados: a construção da diversidade da agricultura na ruralidade contemporânea. In: SCHNEIDER, S.; GAZOLLA, M. (Org.). Os atores do desenvolvimento rural: perspectivas teóricas e práticas. Porto Alegre: Editora da UFRGS, 2011. p. 67-89.

DEPARTAMENTO DE ESTUDOS SOCIOECONÔMICOS RURAIS (DESER). Tabaco: da produção ao consumo - Uma cadeia da dependência. Curitiba, 2010.

FREITAS, T. D. et al. Os meios e as condições de vida no espaço rural: o caso das famílias produtoras de tabaco em Arroio do Tigre (RS) e Laranjeiras do Sul (PR). REDES, Santa Cruz do Sul, v. 20, n. 3 - Suplemento, p. 138-162, set./dez. 2015.

GAZZOLA, M. Conhecimentos, produção de novidades e ações institucionais: cadeias curtas das agroindústrias familiares. 2012. Tese (Doutorado em Desenvolvimento Rural), Programa de Pós-Graduação em Desenvolvimento Rural, Faculdade de Ciências Econômicas, UFRGS, Porto Alegre, 2012.

GEELS, F. W. Understanding system innovations: a critical literature review and a conceptual synthesis. In: ELZEN, B.; GEELS, F. W.; GREEN, K. System Innovation and the transition to sustainability: theory, evidence and policy. Cheltenham: Northampton: Edward Elgar, 2004. p. 19-47. 
GOODMAN, D. The quality turn and alternative food practices: reflections and agenda. Journal of Rural Studies, [S.I.], v. 19, p. 1-7, 2003.

GRISA, C. As redes e as instituições do Programa de Aquisição de Alimentos (PAA). Revista Brasileira de Gestão e Desenvolvimento Regional, Taubaté, v. 6, n. 2, p. 97-129, 2010.

GRISA, C. Políticas públicas para a agricultura familiar no Brasil: produção e institucionalização das ideias. 2012. Tese (Doutorado em Desenvolvimento, Agricultura e Sociedade), Programa de Pós-Graduação de Ciências Sociais em Desenvolvimento, Agricultura e Sociedade, Instituto de Ciências Humanas e Sociais, UFRRJ, Rio de Janeiro, 2012.

INSTITUTO BRASILEIRO DE GEOGRAFIA E ESTATÍSTICA- IBGE. Sistema IBGE de Recuperação Automática: SIDRA. Disponível em: <http://www.sidra.ibge.gov.br/>. Acesso em: mar. 2016.

ILBERY, B. et al. Product, process and place: an examination of food marketing and labelling schemes in Europe and North America. European Urban and Regional Studies, London, v. 12, n. 2, p. 116-132, 2005.

LONG, N. Sociología del desarrollo: una perspectiva centrada en el actor. México: Ciesas, 2007.

LONG, N.; PLOEG, J. D. van der. Heterogeneity, actor and structure: towards a reconstitution of the concept of structure. In.: BOOTH, D. (org) Rethinking social development: theory, research and practice. Essex: Longman Scientific and Technical. 1994, p. 62-89.

LUDTKE, R. C. et al. Iniciativas de diversificação ao cultivo do tabaco no município de Santa Cruz do Sul - RS: um estudo de caso. Extensão Rural, Santa Maria, v. 23, n. 4, p. 24-45, out./dez. 2016.

MARQUES, F. C. Nicho e novidade: nuanças de uma possível radicalização inovadora na agricultura. In.: SCHNEIDER, S.; GAZOLLA, M. (Org.). Os atores do desenvolvimento rural: perspectivas teóricas e práticas. Porto Alegre: Editora da UFRGS, 2011. p. 189-204.

MENGEL, A. A. Tratados internacionais e disputas locais: a Convenção Quadro para o Controle do Tabaco e as disputas entre os atores da cadeia produtiva no Brasil. 2011. Dissertação (Mestrado em Desenvolvimento, Agricultura e Sociedade), Programa de Pós-Graduação de Ciências Sociais em Desenvolvimento, Agricultura e Sociedade, Instituto de Ciências Humanas e Sociais, UFRRJ, Rio de Janeiro, 2011.

OLIVEIRA, D.; ARAÚJO, J. P. Produção de novidades na transição agroecológica: uma análise de iniciativas no sul e nordeste do Brasil. In.: SCHNEIDER, S. et al. (Orgs.). Sementes e brotos da transição: inovação, poder e desenvolvimento em áreas rurais do Brasil. Porto Alegre: Editora UFRGS, 2014. p. 165-192. 
OLIVEIRA, D. et al. Produzindo novidades na agricultura familiar: agregação de valor e agroecologia para o desenvolvimento rural. Cadernos de Ciência \& Tecnologia, Brasília, v. 28, n. 1, p. 17-49, jan./abr. 2011.

OOSTINDIE, H.; BROEKHUIZEN, R. van. The dinamics of novelty production. In: PLOEG, J. D. van der; MARSDEN, T. (Orgs.) Unfolding webs: the dynamics of regional rural development. Assen: Van Gorgum, 2008. p. 68-86.

PAULILO, M. I. S. Produtor e agroindústria: consensos e dissensos. Florianópolis: UFSC, 1990.

PERONDI, M. A. et al. Prospecção de meios de vida alternativos ao cultivo do tabaco no Sudoeste do Paraná. Cadernos de Ciência \& Tecnologia, Brasília, v. 28, n. 3, p. 675-696, set./dez. 2011.

PLOEG, J. D. van der. et al. On Regimes, Novelties, Niches and Co-Produção. In: PLOEG, J. D. van der; WISKERKE, J.S.C. Seeds of transition. Assen: Van Gorcumm, 2004. p. 1-30.

PLOEG, J. D. van der. Camponeses e impérios alimentares: luta por autonomia e sustentabilidade na era da globalização. Porto Alegre: Editora da UFRGS, 2008.

PORTO, S. I. Programa de Aquisição de Alimentos (PAA): política pública de fortalecimento da agricultura familiar e da agroecologia no Brasil. 2014. Dissertação (Mestrado em Agroecologia), Programa Oficial de Postgrado Agroecología, Universidad Internacional de Andalucía, Baeza, 2014.

REDIN, E. Entre o produzir e o reproduzir na agricultura familiar fumageira de Arroio do Tigre. 261 f. Dissertação (Mestrado em Extensão Rural), Programa de Pós-Graduação em Extensão Rural, UFSM, Santa Maria, 2011.

RIBEIRO, M. F. S. et al. A Diversificação como Estratégia de Substituição do Cultivo do Tabaco em uma Propriedade Familiar no Sudeste Paranaense. Revista Paranaense de Desenvolvimento, Curitiba, v. 36, n. 129, p. 171-182, jul./dez. 2015.

ROCHA, J. H.; ANJOS, F. S. dos. A sociologia econômica e os mercados protegidos: um arcabouço teórico e analítico para o Programa de Aquisição de Alimentos. Extensão Rural, Santa Maria, v. 20, n. 2, p. 30-61, mai./ago. 2013.

RUDNICKI, C. P. S. et al. As diferentes faces da confiança na produção do tabaco no Rio Grande do Sul, Brasil: a relação dos agricultores com os orientadores técnicos agrícolas. REDES, Santa Cruz do Sul, v. 19, n. 2, p. 224-241, maio/ago. 2014.

RUDNICKI, C. P. S. As relações de confiança no sistema integrado da produção de tabaco (SIPT) no Rio Grande do Sul/Brasil. 2012. Tese (Doutorado em Desenvolvimento Rural), Programa de Pós-Graduação em Desenvolvimento Rural, Faculdade de Ciências Econômicas, UFRGS, Porto Alegre, 2012. 
RUDNICKI, C. S.; GUERIN, Y. S. As mediações na trajetória de vida dos agricultores do tabaco no Rio Grande do Sul. Revista Extensão Rural, DEAER - CCR - UFSM, v. 20 , n. 1, p. 27-36, jan./mar. 2014.

SARTORELLI, A.; RAMBO, A. G. Os meios e as condições de vida dos agricultores familiares produtores de tabaco - um estudo no município de Laranjeiras do Sul/PR. Extensão Rural, Santa Maria, Santa Maria, v. 21, n. 4, p. 131-173, out./dez. 2014.

SCHNEIDER, S.; GAZOLLA, M. Os atores entram em cena. In.: SCHNEIDER, S.; GAZOLLA, M. (Org.). Os atores do desenvolvimento rural: perspectivas teóricas e práticas. Porto Alegre: Editora da UFRGS, 2011. p. 11-17.

SILVA, L. X. Análise do complexo agroindustrial fumageiro sul-brasileiro sob o enfoque da economia dos custos de transação. 2002. Tese (Doutorado em Economia), Faculdade de Ciências Econômicas, UFRGS, Porto Alegre, 2002.

SILVA, L. X.; TZOVENOS, H. K. Ambiente internacional atual do mercado de tabaco: interpretações para o caso brasileiro. In: Congresso da Sociedade Brasileira de Administração, Economia e Sociologia rural, 51, 2013, Belém, Anais..., Belém, SOBER, 2013.

SILVEIRA, R. L. L.; DORNELLES, M. Mercado mundial de tabaco, concentração de capital e organização espacial. Notas introdutórias para uma geografia do tabaco. Scripta Nova, Barcelona, v. 14, n. 338, p. 1-27, out. 2010.

TRICHES, R. M.; SCHNEIDER, S. Reconstruindo o "elo perdido": a reconexão da produção e do consumo de alimentos através do programa de alimentação escolar no município de Dois Irmãos (RS). Segurança Alimentar e Nutricional, Campinas, n. 17, p. 1-15. 2010.

TROIAN, A. et al. A sustentabilidade na percepção ambiental de produtores de tabaco e de agentes de desenvolvimento: o caso de Arvorezinha (RS). REDES, Santa Cruz do Sul, v. 17, n. 3, p. 26-49, set./dez. 2012.

TROIAN, A.; BECKER, C. Diversificação de cultivos em áreas produtoras de tabaco: desafios dos jovens rurais gaúchos. In: Congresso da Sociedade Brasileira de Administração, Economia e Sociologia rural, 53, 2015, João Pessoa, Anais..., João Pessoa, SOBER, 2015.

VARGAS, M. A.; OLIVEIRA, B. F. Estratégias de diversificação em áreas de cultivo de tabaco no Vale do Rio Pardo: uma análise comparativa. RESR, Piracicaba, v.50, n. 1, p. 175-92, jan./mar. 2012. 